\title{
Cognitive Semantics and Axiology: A New Proposal to Study Metaphor in Economics Advertising Discourse
}

\author{
$\mathrm{M}^{\mathrm{a}}$ Enriqueta Cortés de los Ríos \\ University of Almería \\ mecortes@ual.es
}

\begin{abstract}
In this paper, we provide the groundwork for an analysis of metaphor from the point of view of cognitive linguistics. This study attempts to show an interpretation of metaphor which is different from a mere comparison or substitution function and is by no means a deviant or marginal process. We refer to metaphor not only as a matter of language but also as one of thought, that is, in the way we conceptualize one mental domain in terms of another. The specific focus is to analyse the metaphors used in advertising to transfer values to a banking institution. As a result, we aim to demonstrate that cognitive semantics and axiology are closely related.
\end{abstract}

\section{Introduction}

As part of a revival of interest in semantics there has been a burgeoning growth in concern with metaphor. Since the appearance of Cognitive Linguistics ${ }^{1}$ in the mid 1970 s, this figure has received the greatest amount of attention by scholars such as Lakoff and Johnson (1980), Lakoff (1987) and Turner (1987) who have devoted their research to studying this phenomenon. Lakoff and his associates postulate that metaphor, far from being mere word play and ornament, is fundamental to cognition. Turner (1987:1) reminds us that "Classical Rhetoric too saw metaphor as reflecting fundamental patterns of thought before its eventual preoccupation with style". As a matter of fact, the traditional perspective contended that metaphorical language was a secondary, derived linguistic adornment associated with 
literary texts. This view dates back to Aristotle and rests on the idea, given in his Poetics (1459), that the greatest thing by far is to be master of metaphor. However, recent discussion has demonstrated the essential confusion inherent in such a claim. In actual practice, metaphors form part of our ordinary linguistic competence.

For the cognitive approach metaphor is not understood as a speaker's violation of the rules of competence, as generative linguistics suggested. Rather, the cognitive paradigm sees it as a means whereby more abstract and intangible areas of experience can be conceptualized in terms of familiar and concrete domains. In fact, the idea that conceptual metaphors systematically structure the way that many domains are understood has subsequently been used to explain the nature of emotion concepts (Lakoff and Köveceses, 1987; Kövecses, 1990) and the meaning of idioms (Gibbs and O'Brien, 1990). Metaphor is thus motivated by a search for understanding. The concept we try to understand is called the target domain, and the concept which is used for this purpose is called the source domain. Knowledge of the latter allows us to reason about the former. This mapping is referred to by Lakoff and Johnson as a structural metaphor.

The cognitive view maintains that much of our understanding of everyday experience is structured in terms of metaphor. It shapes our world by determining the way in which we perceive categories of people and objects. In short, metaphors are idealized cognitive models or ICMs. ${ }^{2}$ According to Lakoff (1987:68) "these cognitive structures are the way in which human beings organize knowledge".

The aforementioned scholar and others have reached the conclusion that this figure, that is, cross-domain mapping, is absolutely central to ordinary natural language semantics, and that the study of literary metaphor is an extension of the study of everyday metaphor. However, we must bear in mind that this approach is not entirely new. The cognitive view of metaphor was already anticipated by Richards (1936) and in Black's interactional theory (1962) and was considered as a systematized form by Reddy (1979).

Cognitive-axiological linguistic research was initiated and developed by Krzeszowski (1990, 1993 and 1997) in Poland and later extended to Belgium (Pauwels and SimonVanderbergen, 1993, 1995; Simon-Vanderbergen, 1995). According to this perspective of study, Krzeszowski (1997: 24) maintains:

Not all "things" exist in the material world. Some perhaps most, are only results of human conceptualizations. Things such as friendship, love, mathematics, tragedy, motherhood, and hosts of others, including values themselves, do not exist outside human experience as entities independent of human conceptualization. In fact, they are results of human cognitive processes and specifically the process of conceptualization.

Krzeszowski $(1993,1997)$ justifies the metaphorical nature of the good-bad polarity and empirically bases the integration of the axiological component on the idealized cognitive models. Similarly, this linguist states that preconceptual image schemata should include the axiological parameter MORE-LESS or the positive-negative scale. Pauwels and SimonVanderbergen (1995) have researched into the role of values, using a different approach to that of the Polish linguist. They identify the elements that determine a positive or negative 
value judgement, concentrating on the metaphorical projections from the domain of the parts of the body to that of the linguistic action. These authors place great emphasis on context. In Spain, Felices Lago $(1994,1996)$ established the concept of applied axiology to refer to the evaluation classeme as an instrument to analyse discourse types. ${ }^{3}$

Precisely, advertising discourse, linked to communication factors, either verbal or nonverbal, is particularly suitable for doing research on the linguistic codification of values. As a result, the cognitive theory of metaphor is, in our opinion, the most useful way to carry out an axiological analysis of advertising discourse. If, as Lakoff and Johnson (1980: 5) argue, "the essence of metaphor is understanding and experiencing one kind of thing in terms of another", the possibilities metaphor offers for advertising are obvious. Indeed, writing on this matter, Williamson (1978: 23) stated that "advertising borrows characteristics and affective values from more or less structured domains of human experience and transposes these to the product advertised". The symbolization process which leads us to associate certain objects with values forms part of our cognitive activity, Advertising stimulates the mental processes by means of which we create images and associations. As a consequence, the metaphorical language used in advertising discourse is very relevant. The advertiser looks for the most effective metaphor, that is, the concept which is best associated with the firm advertised, taking into account the reader"s physical and cultural experience.

In short, in the present paper we would like to place emphasis on metaphors and to show how cognitive-axiological theory can be applied to the discourse of banking print advertising. As a result, we will try to take a step further towards understanding advertising discourse.

\section{Metaphor in advertising}

It is obvious that large numbers of metaphors are created in order to denote a special positive value or to suggest various meaning associations which are basically positive. Thus, advertisers achieve their goals by emphasizing certain values through the manipulation of language, "the loaded weapon". As Pollay (1984:111) pointed out:

Values are probably the single most important dimension of advertising. Values are important from both the sender's and the receiver's points of view since it is the "goodness" of products that lies at the heart of the whole communication. Despite the economist's concern for information transmittal, it is clear that advertising's primary function is to transmit value to a product and brand, and information is of tactical usefulness only to the extent that consumers are responsive to it, effecting a communication of values.

For advertisers the service provided by banking institutions is what they want to present to the customer in the hope of promoting it, and they do so by showing its positive aspects or values to prove that it is desirable. For the cognitive linguist the focus is on how the positive, desirable aspects of the service are represented. This can be done in two ways. 
Firstly, explicitly by verbalizing how safe, prestigious or profitable the advertised bank is for the customer. Secondly, by means of indirect strategies, the most important of which is, perhaps, to establish a metaphorical link with a domain conventionally representing the desired quality. Images such as fertile ground or a boat are used to indicate profitability and safety respectively. Precious stones suggest prestige. On the surface these metaphors seem to offer all the advantages a metaphor can provide in terms of conceptual support. This includes the richness of a well-structured source domain (ship, precious stones), available for mapping onto the target domain (the advertised bank). Consider all the details that come to mind when one thinks of ships or precious stones. As Ungerer comments (forthcoming) "source domains are -on the whole- prestuctured for positive aspects, which can be carried over into the target domain in a seemingly effortless and natural way". On this matter, Forceville (1996: 69) states that "an advertiser forges a link between the product and something that already possesses the characteristic(s) he desires to claim for the product".

As a result, it goes without saying that metaphor is particularly attractive to advertisers. The aim of an advertiser is to persuade a prospective client to buy his/her product, service or idea. For this purpose he forges a link between the product and the value he desires to promote it. By producing a metaphorical utterance, the advertiser invites his audience to process it and derive some assumptions about the value which he associates with the product or service. In fact, the advertiser of banking institutions selects different images by virtue of the values he/she wants to transmit. Most frequently, the images are accompanied by verbal support, that is, conceptual metaphor. This can be illustrated by the following examples of advertisements. ABN AMRO Bank (The Wall Street Journal, May 24, 1993) showed a chest expander to communicate its value. The slogans used by the advertiser were the following: The expanding world of the treasurer. In Treasury Management a bank should show brains, not just muscle. As a result, the reader associated the value "globalization" (a very frequent value in banks) with the bank advertised. Likewise, Bank Julius Baer (Fortune International, September 6, 1993) chose Noah's ark, into which different animals could be seen entering. The slogan which accompanied this image was "Some only offer umbrellas. But Bank Julius Baer offers more". The advertiser wanted the reader to associate safety with the advertised bank. ${ }^{4}$

Consequently, communicators design metaphors to drive consumer thinking and behaviour using prospective clients' metaphors, that is to say, in everyday spoken language. As Zaltman and Coulter (1995: 38) postulated:

Metaphors are the key windows/mechanisms for viewing consumer thought and feelings and for understanding. For the most part, it is only through Lakoff and Johnson's metaphors that we can understand consumer thinking and behaviour and thus learn how to develop and market goods and services successfully. Even behaviour and thoughts are themselves metaphors for one another.

From this perspective, it seems to be that metaphor is of vital importance since it solidifies a whole set of perceptions about a concept, which then dictate how we can use it, how we can understand its meaning, and how we can behave with respect to it. Its frequency 
of use also makes the metaphor seem natural as the meaning of the concept, though it may be only a partial truth about it. In short, the meaning transferred across domains can be affective, as well as cognitive (Cameron and Low, 1999: 82). The experiential "logic" of the source domain (i.e its inference patterns and associated value judgements) is generally preserved in the metaphorical mapping (Lakoff 1990: 54).

The recognition of the power that cognitive metaphor has may enable communicators deliberately to choose a concept which is convenient to their aims. Hence, an advertiser selects a particular metaphor to persuade and influence consumers. As a result, metaphor can easily be exploited for the purpose of persuasion and manipulation (Roher, 1995). This also holds for advertising discourse.

\section{The verbalization of metaphor in advertising}

Pollay's formulation is useful to codify values since this marketing theorist developed a suitable methodological approach to analyse themes in modern advertising. Pollay (1984: 117-123) divided values into two types: dominant and subordinate. Dominant themes are those that are the key elements of advertisements' gestalt, or first impression. They are manifest in illustrations and headings, titling and major captions. Subsidiary themes are those additional themes included in the illustration, or embodied in the fine print of the body copy.

Values are introduced by verbal metaphors and pictorial metaphors. Metaphors illustrate Lakoff and Johnson's notion of conceptual systems in the sense that they can be said to be based on structural or conceptual metaphors. ${ }^{5}$ The illustration of a dominant value is taken from Abbey National Bank (The Economist, October 2, 1993): It's time you reaped the benefits of Jersey's fertile financial environment.

If we pursue Lakoff and Johnson's line of thought (1980:5) when they stated that "understanding and perceiving one kind of thing in terms of another is the essence of metaphor", the analysis of the previous example shows that we can conceptualize in advertising an initial mapping between two different semantic fields in the following way: ABBEY NATIONAL BANK IS FERTILE GROUND, that is, the concept we try to understand, the target domain (Abbey National Bank), and the concept which is used for this purpose, the source domain (fertile ground). As can be seen from this expression, an association is created between this banking company and the fertility of the ground.

Furthermore, in order to substantiate this mapping, we shall have recourse to the evidence provided by Lakoff (1993: 207) who has postulated that conceptual projections are tightly structured. There are ontological correspondences according to which entities and goals in the target domain correspond to the source domain. Some ontological correspondences according to the above illustration are the following:

Abbey National Bank is a recipient.

Abbey National Bank can be filled with seeds. 
Abbey National Bank's goal corresponds to a farmer's goal: to grow a crop in fertile ground (to make a profit).

The mapping includes epistemic correspondences, in which knowledge about fertile ground is mapped onto knowledge about a banking institution (Abbey National Bank). Such correspondences permit us to reason about a banking institution using the knowledge we use to reason about fertile ground. We can illustrate this as follows:

Source domain: Seeds are put into the fertile ground so that they can grow.

Target domain: Abbey National Bank's "fertile ground" can be sown with seeds in which plants (money) can grow.

Following Pollay's formulation (1984: 111) that "advertising's primary function is to transmit value to a product and brand", a second mapping has to be verbalized. The target domain is the firm or product advertised, and the source domain is the value with which the advertiser identifies it. As a result, this leads us to consider that the value with which the advertiser identifies Abbey National Bank is "profitability" in his desire to persuade readers to invest in it. Bearing this in mind, we can regard the Abbey National Bank/profitability relation as a metaphor. Consequently, it can be verbalized as ABBEY NATIONAL BANK IS PROFITABILITY. Obviously, the correspondences of this second mapping are similar to the first one due to the fact that previously the value "profitability" has been understood by a concrete concept: fertile ground.

Therefore, what constitutes the ABBEY NATIONAL BANK IS PROFITABILITY metaphor is not any particular word or expression. It is the ontological and epistemic mapping across conceptual domains based on the way we function in our physical and cultural experience. Furthermore, this mapping is reinforced by the image in which we can see a group of farmers bringing in the harvest. In this picture we can identify the following iconic metaphors: (1) the fertile land of Jersey represents the financial fertility of Abbey National Bank, (2) the farmers symbolize Abbey National Bank's employees and (3) the harvest represents the profits made by investment in the advertised bank.

Indeed, the fact of the matter is that we map a metaphorical concept such as A BANK IS SAFE/PROFITABLE etc. because these associations emerge in our culture in terms of the conceptualization that people have about a banking institution. Lakoff and Johnson (1980: 117-118) state that experiences are a product of our bodies (perceptual and motor apparatus, mental capacities, emotional makeup, etc.), of our interactions with our physical environment (moving, manipulating objects, etc.) and our interactions with other people within our culture (in terms of social, political, economic, and religious institutions). Thus the concept of a banking institution leads us to perceiving safety, calmness, etc. as a product of our bodies, to perceiving comfort, amiability, etc. as a product of our interactions with our physical environment, and to perceiving interaction with other companies within a specific economic sector. 


\section{Conclusion}

Axiology applied to the theoretical foundation of cognitive semantics establishes the grounds of this research. In all probability, we have carried out the first cognitiveaxiological study about banking advertising discourse. In our opinion, we have demonstrated that the semantic theories employed, both cognitive and axiological, are closely related.

In this paper we have provided the theoretical background to study metaphor in advertising. The fact that advertisers use metaphor so frequently suggests that it must necessarily perform some useful function. As a result, we must conclude that metaphor has two functions in advertising discourse. Firstly, a cognitive function because it is not only used as a tool to express ideas by means of language, but also as a reflection of our thinking. It is a semiotic strategy used by advertisers to build up the meaning of a concept by means of another one taking into account the body experience and culture of the reader. Secondly, a rhetorical function because its intended use owes much to the advertiser"s specific purpose. Deliberate use of metaphor in print advertising discourse pursues a pragmatic aim: to persuade the reader and influence his behaviour.

The study of values in advertising discourse from a linguistic perspective can help to stimulate interdisciplinary studies. This research could be applied to other fields such as law, economics and politics.

\section{Notes}

1. The advent of Cognitive Linguistics has had far-reaching consequences for the understanding not only of metaphor but also image schemas and metonymy.

2. The purpose of ICMs is to represent reality and they result from a process of idealization of reality. See Lakoff (1987).

3. So as to avoid terminological confusion, Felices has coined the neologism axioematic (a proposal for a sub-discipline of classematics) to refer to the analysis, from a fundamentally linguistic point of view, of the encoding of the predominant values in a specific discourse. His methodological line is inspired on the lexematic-functional model of Martín Mingorance (1984).

4. These examples come from Cortés de los Ríos (2001), Ph. D. Thesis.

5. Lakoff (1993) distinguishes between conceptual metaphor and the metaphorical expression. The former is the conceptual mapping between domains. The latter refers to the language that expresses that mapping.

\section{Works Cited}

Black, Max. (1962): Models and Metaphors: Studies in Language and Philosophy. Ithaca, New York: Cornell University Press.

Cameron, Lynne and Graham Low (1999): "Metaphor". Language Teaching 32: 77-96.

Cortés de los Ríos, M. E. (2001): Análisis cognitivo axiológico del discurso publicitario en la prensa económico-empresarialen lengua inglesa. $\mathrm{PhD}$ Thesis. University of Almeria, Servicio de Publicaciones. 
Felices Lago, Ángel (1994): "El análisis axiológico de los discursos característicos del inglés empresarial" . In A. Gimeno Sanz (ed.) Colección Idiomas para Fines Especificos. A Practical Approach/Un Enfoque Práctico. Valencia: Universidad Politécnica, 2: 39-56.

. (1996): "Axiomatic analysis of brand names in English: A semantic-pragmatic approach to branding": In G. Budin (ed.) Multilinguialism in Specialist Communication (Proceedings of the 10th European Symposium on Language for Special Purposes). Viena: International Institute for Terminology Research-Infoterm, 2: 991-1010.

Forceville, Charles. (1996): Pictorial Metaphor in Advertising. London: Routledge.

Gibbs, R.W. and J.E. O'Brien (1990): "Idioms and mental imagery: The metaphorical motivation for idiomatic meaning". Cognition 36: 35-68.

Kövecses, Zoltán. (1990): Emotion Concepts. New York: Springer-Verlag.

Krzeszowski, Tomasz. P. (1990): "The axiological aspect of idealized cognitive models". In J. Tomaszcyk and B. Lewandoska (eds.) Meaning and Lexicography. Amsterdam: Benjamins, 135-165.

. (1993): "The axiological parameter in preconceptual image schemata". In R.A. Geiger and B.Rudzka-Ostyn (eds.) Conceptualizations and Mental Processing in Language. Berlin: Mouton de Gruyter, 307-330.

. (1997): Angels and Devils in Hell. Elements of Axiology in Semantics. Warszawa: Energegia.

Lakoff, George. (1987): Women, Fire and Dangerous Things: What Categories Reveal about the Mind. Chicago: Chicago University Press.

. (1990): "The Invariance Hypothesis: is abstract reason based on image schemas?". Cognitive Linguistics 1 (1): 39-74.

(1993): "The contemporary theory of metaphor". In Ortony, ed., Metaphor and Thought. Cambridge: Cambridge University Press, 202-251.

Lakoff, George and Johnson, Mark. (1980): Metaphors We Live By. Chicago: Chicago University Press.

Lakoff, George. and Kövecses, Zoltán. (1987): "The cognitive model of anger inherent in American English". In Holland and Quinn (eds.) Cultural Models in Language and Thought. New York: Cambridge University Press, 195-221.

Pauwels, Paul.and Anne-Marie Simon-Vandenbergen (1993): "Value judgement in the metaphorization of linguistic action". In R.A. Geiger and B. Rudzka-Ostyn (eds.) Conceptualizations andMental Processing in Language. Berlin: Mouton de Gruyter, 331-367. . (1995): "Body parts in linguistic action: underlying schemata and value judgements". In L. Goosens, P. Pauwels et al. (eds.) By Word of Mouth: Metaphor, Metonymy and Linguistic Action in a Cognitive Perspective. Amsterdam: Benjamins, 35-70.

Pollay, Richard (1984): "The identification and distribution of values manifest in print advertising, 1900-1980". In R.E. Pitts and A. G. Woodside (eds.) Personal Values and Consumer Psychology. Lexinton: Lexinton Press, 11-129.

Reddy, Michael (1979): "The conduit metaphor: A case of frame conflict in our language about language". In A. Ortony (ed.) Metaphor and Thought. Cambridge: Cambridge University Press, 164-201.

Richards, Ivor. A. (1936): The Philosophy of Rhetoric. New York: Oxford University Press.

Roher, T. (1995): "The metaphorical logic of (Political) Rape: The new wor(l)d order". Metaphor and Symbolic Activity 10 (2): 115-137. 
Simon-Vanderbergen, Anne-Marie (1995): "Assessing linguistic behaviour: A study of value judgements". In L. Goosens, P. Pauwels et alli (eds.) By Word of Mouth: Metaphor, Metonymy and Linguistic Action in a Cognitive Perspective. Amsterdam: Benjamins, 71-123.

Turner, Mark (1987): Death is the Mother of Beauty: Mind, Metaphor, Criticism. Chicago: Chicago University Press.

Ungerer, Friedrich (forthcoming): "Muted metaphors and the activation of metonimies in advertising". In A. Barcelona Sánchez (ed.) Metaphor and Metonymy at the Crossroads. A Cognitive Perspective. Berlin/New York: Mouton de Gruyter.

Williamson, John (1978): Decoding Advertisements: Ideology and Meaning in Advertising. London: Marion Boyars.

Zaltman, Gerald and Coulter, Robin (1995): "Seeing the voice of the consumer: Metaphor-based advertising research". Journal of Advertising Research 35(4): 35-50. 